OPEN ACCESS

Edited by: Carolina Elena Girometta,

University of Pavia, Italy

Reviewed by:

Fei Cao,

Hebei University, China Madhuree Kumari,

Indian Institute of Science (IISC), India

*Correspondence.

Da-Yong Shi

shidayong@sdu.edu.cn

Specialty section: This article was submitted to

Microbiotechnology,

a section of the journal

Frontiers in Microbiology

Received: 30 March 2021

Accepted: 06 May 2021

Published: 11 June 2021

Citation

Shi T, Li X-Q, Zheng L, Zhang $Y-H$, Dai J-J, Shang E-L, YU Y-Y, Zhang Y-T, Hu W-P and Shi D-Y (2021) Sesquiterpenoids

From the Antarctic Fungus

Pseudogymnoascus sp. HSX2\#-11.

Front. Microbiol. 12:688202.

doi: 10.3389/fmicb.2021.688202

\title{
Sesquiterpenoids From the Antarctic Fungus Pseudogymnoascus sp. HSX2\#-11
}

\begin{abstract}
Ting Shi', Xiang-Qian Li ${ }^{1,2}$, Li Zheng, ${ }^{3,4}$, Ya-Hui Zhang5,6, Jia-Jia Dai', Er-Lei Shang ${ }^{7}$, Yan-Yan Yu' ${ }^{1}$, Yi-Ting Zhang ${ }^{1}$, Wen-Peng $\mathrm{Hu}^{1}$ and Da-Yong Shi ${ }^{1,2 *}$

'State Key Laboratory of Microbial Technology, Institute of Microbial Technology, Shandong University, Qingdao, China, 2 Laboratory for Marine Drugs and Bioproducts of Qingdao National Laboratory for Marine Science and Technology, Qingdao, China, ${ }^{3}$ Key Laboratory of Marine Eco-Environmental Science and Technology, First Institute of Oceanography, Ministry of Natural Resources, Qingdao, China, ${ }^{4}$ Laboratory for Marine Ecology and Environmental Science, Qingdao Pilot National Laboratory for Marine Science and Technology, Qingdao, China, ${ }^{5}$ Key Laboratory of Marine Drugs, The Ministry of Education of China, School of Medicine and Pharmacy, Ocean University of China, Qingdao, China, ${ }^{6}$ Laboratory for Marine Drugs and Bioproducts, Qingdao National Laboratory for Marine Science and Technology, Qingdao, China,

${ }^{7}$ State Key Laboratory of Pharmaceutical Biotechnology, School of Life Sciences, Nanjing University, Nanjing, China
\end{abstract}

The fungal strains Pseudogymnoascus are a kind of psychrophilic pathogenic fungi that are ubiquitously distributed in Antarctica, while the studies of their secondary metabolites are infrequent. Systematic research of the metabolites of the fungus Pseudogymnoascus sp. HSX2\#-11 led to the isolation of six new tremulane sesquiterpenoids pseudotremulanes A-F (1-6), combined with one known analog 11,12-epoxy-12 $\beta$-hydroxy-1-tremulen-5-one (7), and five known steroids (8-12). The absolute configurations of the new compounds (1-6) were elucidated by their ECD spectra and ECD calculations. Compounds 1-7 were proved to be isomeride structures with the same chemical formula. Compounds 1/2, 3/4, 1/4, and 2/3 were identified as four pairs of epimerides at the locations of C-3, C-3, C-9, and C-9, respectively. Compounds $\mathbf{8}$ and $\mathbf{9}$ exhibited cytotoxic activities against human breast cancer (MDAMB-231), colorectal cancer (HCT116), and hepatoma (HepG2) cell lines. Compounds 9 and $\mathbf{1 0}$ also showed antibacterial activities against marine fouling bacteria Aeromonas salmonicida. This is the first time to find terpenoids and steroids in the fungal genus Pseudogymnoascus.

Keywords: Antarctic fungus, Pseudogymnoascus sp. HSX2\#-11, sesquiterpenoids, steroids, cytotoxicity, antibacterial activity

\section{INTRODUCTION}

Tremulanes, a family of sesquiterpenoids with characteristic structures of 5/7 fused bicyclic system, were rarely discovered in nature until 2015 (Guo et al., 2016). However, from 2016 to 2020, about 60 tremulane derivatives were found (Guo et al., 2016; Isaka et al., 2016; Wu, 2016; Chen et al., 2017, 2018; Cong et al., 2020; Wang et al., 2017, 2020; Ding et al., 2018, 2019, 2020a,b; Zhou et al., 2018; Duan et al., 2019; Wu et al., 2019, 2020; He et al., 2020; Lee et al., 2020; Shi et al., 2020; Sun C.-T. et al., 2020), and the number is twice as many as before. Most of them were isolated from the cultures of the basidiomycetes Irpex lacteus (Chen et al., 2018, 2020; Ding et al., 2018, 2019, 2020a,b; 
Zhou et al., 2018; Duan et al., 2019; Wu et al., 2019; Shi et al., 2020; Sun C.-T. et al., 2020; Wang et al., 2020). All the tremulanes isolated from 2016 to 2020 were derived from fungi, except one derivative, which was obtained from a traditional Chinese medicine tabasheer $(\mathrm{Wu}, 2016)$. Some of them were discovered to have different bioactivities, such as tremutin A with the inhibition of the lipopolysaccharide-induced proliferation of B lymphocyte cells (Wang et al., 2020), and 5-demethyl conocenol C showed antifungal activities (Wu et al., 2019).

The extreme environments of Antarctica, including cold, dry climate and intense solar radiations, have nurtured a number of unique microbial resources (Cong et al., 2020). It has been proved that Antarctic microorganisms, especially fungi, have the potential capacity to produce novel secondary metabolites to adapt to the harsh environments (Kwon et al., 2017; Rusman et al., 2018; Yu et al., 2019; Sun C. et al., 2020). Pseudogymnoascus are known as a kind of psychrophilic pathogenic fungi with ubiquitous distribution in Antarctica (Rosa et al., 2020; Santos et al., 2020; Martorell et al., 2021). These fungal strains have been proved to have the abilities to produce cold-adapted enzymes to adapt severe cold Antarctic environment (Loperena et al., 2012; Poveda et al., 2018). Pseudogymnoascus can be antagonistic fungi against potato scab pathogens from potato field soils (Tagawa et al., 2010) and have been certified to be one of the predominant microbial colonizers in the root endosphere and rhizosphere of turfgrass systems (Xia et al., 2021). The extracts of some of Pseudogymnoascus strains exhibit potent bioactivities, such as antimicrobial, herbicidal, and antitumoral activities (Henríquez et al., 2014; Gonçalves et al., 2015; Gomes et al., 2018; Ferrarezi et al., 2019). However, only four studies have been done on the secondary metabolites of the genus Pseudogymnoascus until now, as far as we know, and most of the obtained structures focus on polyketides, showing antimicrobial activities (Figueroa et al., 2015; Guo et al., 2019; Fujita et al., 2021; Shi et al., 2021). Rare studies about the secondary metabolites of these fungi enlighten that there is latent space for searching novel compounds. Pseudogymnoascus sp. HSX2\#-11 was an Antarctic fungus isolated from a soil sample of the Fields Peninsula, which can produce abundant and various secondary metabolites, according to our previous research on the fingerprint spectrum and molecular network of its ethyl acetate extract of the fermentation broth (Shi et al., 2021). Further chemical investigation resulted in the isolation and identification of six new tremulane sesquiterpenoids, pseudotremulanes A-F (1-6), together with one known analog 11,12-epoxy-12 $\beta$-hydroxy1-tremulen-5-one (7; Zhou et al., 2008), and five known steroids, ganodermasides A (8), B (9), and D (10; Weng et al., 2010, 2011), ergosterol (11; Feng et al., 2010), and dankasterone B (12; Amagata et al., 2007; Figure 1). Compounds 8 and 9 exhibited cytotoxicities against human breast cancer cell line MDA-MB-231, colorectal cancer cell line HCT116, and hepatoma cell line HepG2 (Table 3). Compounds 9 and 10 showed antibacterial activity against marine fouling bacteria Aeromonas salmonicida. Here, we address the isolation, structure elucidation, and biological activity evaluation of the isolated compounds.

\section{EXPERIMENTAL SECTION}

\section{General Experimental Procedures}

Optical rotations were measured on a JASCO P-1020 digital polarimeter (JASCO, Japan). The UV spectrum was recorded using an Implen Gmbh NanoPhotometer N50 Touch (Implen, Germany). ECD spectra were obtained on a Jasco J-815150S circular dichroism spectrometer (JASCO, Japan). NMR spectra were recorded on a Bruker AVANCE NEO (Bruker, Switzerland) at $600 \mathrm{MHz}$ for ${ }^{1} \mathrm{H}$ and $150 \mathrm{MHz}$ for ${ }^{13} \mathrm{C}$ in $\mathrm{CDCl}_{3}$. Chemical shifts $\delta$ were recorded in ppm using TMS as the internal standard. HR-APCI-MS spectra were measured on a Thermo Scientific LTQ Orbitrap XL spectrometer (Thermo Fisher Scientific, Bremen, Germany). HPLC separation was performed using a Hitachi Primaide Organizer Semi-HPLC system (Hitachi High Technologies, Tokyo, Japan) coupled with a Hitachi Primaide 1430 photodiodearray detector (Hitachi High Technologies, Tokyo, Japan). A Kromasil $\mathrm{C}_{18}$ semi-preparative HPLC column $(250 \times 10$ mm, $5 \mu \mathrm{m}$; Eka Nobel, Bohus, Sweden $)$ was used. Silica gel (200-300 mesh; Qingdao Marine Chemical Group Co., Qingdao, China) and Sephadex LH-20 (Amersham Biosciences Inc., Piscataway, NJ, United States) were used for column chromatography (CC). Precoated silica gel GF254 plates $(20 \times 20 \mathrm{~cm}$, Yantai Zifu Chemical Group Co., Yantai, China).

\section{Fungal Materials}

The soil samples were collected in ice-free areas (about $10 \mathrm{~cm}$ underground) of the Fields Peninsula using sterile spatulas and sterilized WhirlPak bags (Sigma-Aldrich, United States), and were transported to the lab in sealed foam package with dry ice added by airplane, at the Chinese 35th Antarctic expedition in 2019. The fungus Pseudogymnoascus sp. HSX2\#11 was isolated from a soil sample from Fields Peninsula. The strain was deposited at $-80^{\circ} \mathrm{C}$ in the State Key Laboratory of Microbial Technology, Institute of Microbial Technology, Shandong University, Qingdao, China.

The identification of the fungal strain HSX2\#-11 was conducted by the analysis of the $28 \mathrm{~S}$ rRNA gene sequence. The fresh fungal mycelium (about $1.00 \mathrm{mg}$ ) was dispersed in a $50 \mu \mathrm{l}$ lysis buffer for the microorganisms to direct PCR (Takara, Cat\# 9164), saved in metal bath (Yooning, China) at $100^{\circ} \mathrm{C}$ for $30 \mathrm{~min}$ to extract its genomic DNA as the template DNA. The PCRs were performed in a final volume of $50 \mu \mathrm{l}$, which was composed of the template DNA $(3 \mu \mathrm{l})$, ITS1 $(1 \mu \mathrm{l})$, ITS4 $(1 \mu \mathrm{l})$, PrimeSTAR ${ }^{\circledR}$ Max DNA Polymerase $(25 \mu \mathrm{l}$, Takara, Cat\# R045A), and ultrapure water $(20 \mu \mathrm{l})$, under the following procedures: (1) initial denaturation at $98^{\circ} \mathrm{C}$ for $5 \mathrm{~min}$; (2) denaturation at $98^{\circ} \mathrm{C}$ for $30 \mathrm{~s}$; (3) annealing at $55^{\circ} \mathrm{C}$ for $30 \mathrm{~s}$; (4) extension at $72^{\circ} \mathrm{C}$ for $1 \mathrm{~min}$; and (5) final extension at $72^{\circ} \mathrm{C}$ for $10 \mathrm{~min}$. Steps 2-4 were repeated 30 times. The PCR products were then submitted for sequencing (BGI, China) with the primers ITS1 and ITS4. The sequence of HSX2\#-11 was searched in the NCBI nucleotide collection database through the BLAST program. The phylogenetic tree of the top 20 most similar to this fungal sequence identified the strain HSX2\#-11 as 


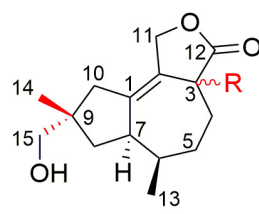

$1 \mathrm{R}=-\mathrm{H}$ $2 \mathrm{R}=\cdots \mathrm{H}$<smiles>[R]C12CC[C@H](C)[C@H]3C[C@](C)(CO)CC3=C1COC2=O</smiles>

$3 \mathrm{R}=\cdots \mathrm{H}$ $4 \mathrm{R}=-\mathrm{H}$<smiles>C[C@H]1CCC2=C(COC2=O)[C@H]2C1C[C@@H](C)[C@H]2O</smiles>

5<smiles>CC1CCC2C(=O)OCC2=C2C1CC(C)(C)C2O</smiles>

6<smiles>CC1C(=O)C[C@H]2C(=C3CC(C)(C)CC31)CO[C@H]2O</smiles>

7

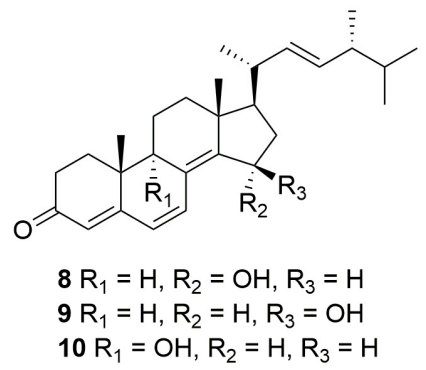

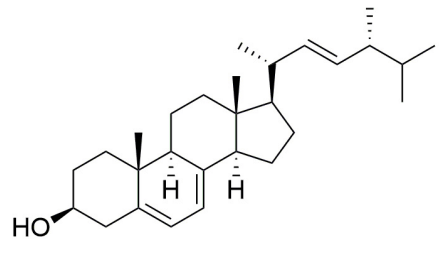

11

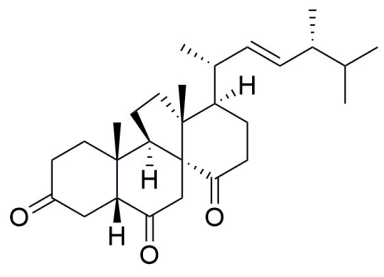

12

FIGURE $\mathbf{1}$ | Structures of compounds 1-12

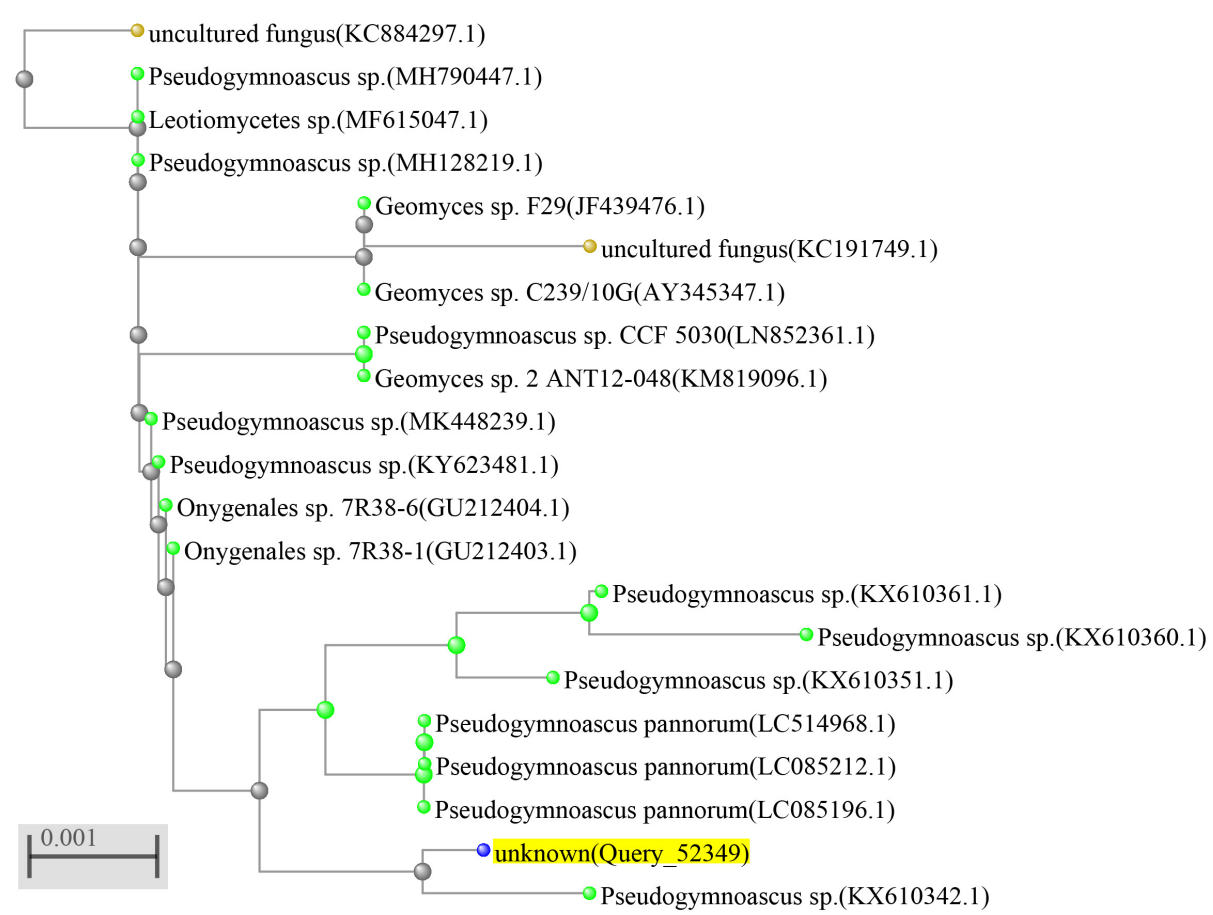

FIGURE 2 | Phylogenetic tree of the fungus Pseudogymnoascus sp. HSX2\#-11.

a Pseudogymnoascus sp. (Figure 2), with GenBank (NCBI) accession number MT367223.1.

\section{Extraction and Isolation}

The fungal strain Pseudogymnoascus sp. HSX2\#-11 was fermented in a PDA liquid medium in 200 Erlenmeyer flasks (300 $\mathrm{ml}$ in each $1,000-\mathrm{ml}$ flask) at $16^{\circ} \mathrm{C}$ in air condition room for 45 days. The culture $(60 \mathrm{~L})$ was filtered to separate the broth from the mycelia. Then the mycelia were extracted three times with EtOAc $(3 \times 4,000 \mathrm{ml})$ and then repeatedly extracted with $\mathrm{CH}_{2} \mathrm{Cl}_{2}-\mathrm{MeOH}(\mathrm{v} / \mathrm{v}, 1: 1)$ three times $(3 \times 4,000 \mathrm{ml})$. The broth was extracted repeatedly with EtOAc $(3 \times 60 \mathrm{~L})$ to get the EtOAc layer. All the extracts were combined and then evaporated to dryness under reduced pressure to afford a residue $(71.5 \mathrm{~g})$. The residue was subjected to vacuum liquid chromatography on silica gel using step gradient elution 
with EtOAc-petroleum ether (PE; 0-100\%) and then with $\mathrm{MeOH}-\mathrm{EtOAc}(0-100 \%)$ to afford eight fractions (Fr.1-Fr.8). Fr.2 was the pure compound $\mathbf{1 1}(89.7 \mathrm{mg})$. Fr.3 was first subjected to the gradient elution of ODS CC with $\mathrm{MeOH}$ in $\mathrm{H}_{2} \mathrm{O}(10-100 \%)$ and then purified by using semipreparative HPLC on an ODS column (Kromasil $\mathrm{C}_{18}, 250 \times 10 \mathrm{~mm}, 5 \mu \mathrm{m}$, $2 \mathrm{ml} / \mathrm{min}$ ) eluted with $85 \% \mathrm{MeOH}-\mathrm{H}_{2} \mathrm{O}$ to give compound $12(2.7 \mathrm{mg})$. Fr.4 was isolated by CC on Sephadex LH-20 eluted with $\mathrm{CH}_{2} \mathrm{Cl}_{2}-\mathrm{MeOH}$ (v/v, 1:1) to afford two fractions (Fr.4.1, Fr.4.2). Fr.4.1 was subjected to silica gel CC eluting with EtOAc-PE (0-50\%) to get three fractions (Fr.4.1.1-4.1.3). Fr.4.1.1 was first purified by HPLC eluted with $60 \% \mathrm{MeOH}-\mathrm{H}_{2} \mathrm{O}$ to give compound 7 (1.9 $\mathrm{mg})$, and then purified by HPLC eluted with $40 \% \mathrm{MeCN}-\mathrm{H}_{2} \mathrm{O}$ to afford $5(0.1 \mathrm{mg})$ and $6(0.2 \mathrm{mg})$. Fr.4.1.2 was subjected on HPLC eluting with $35 \% \mathrm{MeCN}-\mathrm{H}_{2} \mathrm{O}$ to give $\mathbf{1}(0.7 \mathrm{mg})$ and $2(0.7 \mathrm{mg})$. Fr.4.1.3 was separated on HPLC eluting with $30 \% \mathrm{MeCN}-\mathrm{H}_{2} \mathrm{O}$ to get $3(0.6 \mathrm{mg})$ and $4(0.5 \mathrm{mg})$. Fr.4.2 was first separated on silica gel CC eluting with EtOAc-PE (0-50\%), and then purified by HPLC eluting with $75 \% \mathrm{MeOH}-\mathrm{H}_{2} \mathrm{O}$ to gain $8(13.6 \mathrm{mg}), \mathbf{1 0}(3.1 \mathrm{mg})$, and 9 (11.1 mg).

Pseudotremulane A (1): colorless oil; $[\alpha]_{\mathrm{D}}^{20}+8.6$ (c 0.058 , $\mathrm{MeOH}) ; \mathrm{UV}\left(\mathrm{CH}_{2} \mathrm{Cl}_{2}\right) \lambda_{\max }(\log \varepsilon): 224(4.90) \mathrm{nm} ; \mathrm{CD}(3.4 \mathrm{mM}$, $\mathrm{MeOH}) \lambda_{\max }(\Delta \varepsilon) 204(+9.51), 230(-4.31) \mathrm{nm} ;{ }^{1} \mathrm{H}$ and ${ }^{13} \mathrm{C}$ NMR data, see Tables 1, 2; HR-APCI-MS m/z 251.1641 [M+ H] ${ }^{+}$ (calcd for $\mathrm{C}_{15} \mathrm{H}_{23} \mathrm{O}_{3}, 251.1642$ ).

Pseudotremulane B (2): colorless oil; $[\alpha]_{\mathrm{D}}^{20}+13.9$ (c 0.058 , $\mathrm{MeOH}) ; \mathrm{UV}\left(\mathrm{CH}_{2} \mathrm{Cl}_{2}\right) \lambda_{\max }(\log \varepsilon): 223$ (4.82); CD (3.4 mM, $\mathrm{MeOH}) \lambda_{\max }(\Delta \varepsilon) 223(+4.80) \mathrm{nm} ;{ }^{1} \mathrm{H}$ and ${ }^{13} \mathrm{C}$ NMR data, see Tables 1, 2; HR-APCI-MS m/z 251.1641 [M+ H] ${ }^{+}$(calcd for $\left.\mathrm{C}_{15} \mathrm{H}_{23} \mathrm{O}_{3}, 251.1642\right)$.

Pseudotremulane C (3): colorless oil; $[\alpha]_{\mathrm{D}}^{20}+20.6(c 0.050$, $\mathrm{MeOH}) ; \mathrm{UV}\left(\mathrm{CH}_{2} \mathrm{Cl}_{2}\right) \lambda_{\max }(\log \varepsilon): 228$ (4.48); CD (4.0 mM, $\mathrm{MeOH}) \lambda_{\max }(\Delta \varepsilon) 217(+3.05) \mathrm{nm} ;{ }^{1} \mathrm{H}$ and ${ }^{13} \mathrm{C}$ NMR data, see Tables 1, 2; HR-APCI-MS m/z 251.1642 [M+ H] ${ }^{+}$(calcd for $\mathrm{C}_{15} \mathrm{H}_{23} \mathrm{O}_{3}, 251.1642$ ).

Pseudotremulane D (4): colorless oil; $[\alpha]_{\mathrm{D}}^{20}+8.5(c 0.042$, $\mathrm{MeOH}) ; \mathrm{UV}\left(\mathrm{CH}_{2} \mathrm{Cl}_{2}\right) \lambda_{\max }(\log \varepsilon): 223$ (4.88); CD (2.4 mM, $\mathrm{MeOH}) \lambda_{\max }(\Delta \varepsilon) 205(+13.51), 232(-5.56) \mathrm{nm} ;{ }^{1} \mathrm{H}$ and ${ }^{13} \mathrm{C}$ NMR data, see Tables 1, 2; HR-APCI-MS m/z 251.1641 [M+ H] ${ }^{+}$ (calcd for $\mathrm{C}_{15} \mathrm{H}_{23} \mathrm{O}_{3}, 251.1642$ ).

Pseudotremulane E (5): colorless oil; $[\alpha]_{\mathrm{D}}^{20}-75.0$ (c 0.008, $\mathrm{MeOH}) ; \mathrm{UV}\left(\mathrm{CH}_{2} \mathrm{Cl}_{2}\right) \lambda_{\max }(\log \varepsilon): 224$ (5.51); CD (1.2 mM, $\mathrm{MeOH}) \lambda_{\max }(\Delta \varepsilon) 222(-0.29), 247(+1.29) \mathrm{nm} ;{ }^{1} \mathrm{H}$ and ${ }^{13} \mathrm{C}$ NMR data, see Tables 1, 2; HR-APCI-MS m/z 251.1638 [M + H] ${ }^{+}$ (calcd for $\mathrm{C}_{15} \mathrm{H}_{23} \mathrm{O}_{3}, 251.1642$ ).

Pseudotremulane F (6): colorless oil; $[\alpha]_{\mathrm{D}}^{20}+7.9$ (c 0.017, $\mathrm{MeOH}) ; \mathrm{UV}\left(\mathrm{CH}_{2} \mathrm{Cl}_{2}\right) \lambda_{\max }(\log \varepsilon): 221$ (5.17); CD (6.0 mM, $\mathrm{MeOH}) \lambda_{\max }(\Delta \varepsilon) 223(+4.29) \mathrm{nm} ;{ }^{1} \mathrm{H}$ and ${ }^{13} \mathrm{C}$ NMR data, see Tables 1, 2; HR-APCI-MS m/z 251.1641 [M+ H] ${ }^{+}$(calcd for $\mathrm{C}_{15} \mathrm{H}_{23} \mathrm{O}_{3}, 251.1642$ ).

\section{Cytotoxicity Assays}

Cytotoxicities against human breast cancer (MDA-MB-231), colorectal cancer (HCT116), lung carcinoma (A549), pancreatic carcinoma (PANC-1), and hepatoma (HepG2) cell lines were evaluated using the SRB method (Skehan et al., 1990).
Adriamycin was used as a positive control. The cell lines of MDA-MB-231, HCT116, A549, PANC-1, and HepG2 in the logarithmic growth phase were seeded into 96-well plates with 5,000 cells/well $(100 \mu \mathrm{l} /$ well $)$, respectively. After $24 \mathrm{~h}$ of culture, the isolated compounds to be tested were added (the final concentration was shown in Supplementary Table 1), and three replicates were set for each concentration. The dosage of DMSO in the solvent control group was $0.1 \%$ of the maximum dose used in the test group. After $72 \mathrm{~h}$ of drug treatment, $10 \%$ $(\mathrm{m} / \mathrm{v})$ of cold trichloroacetic acid was added to each well to fix the cells. After SRB staining, $150 \mu \mathrm{l} /$ well Tris solution was added to determine the optic density (OD) values at $515 \mathrm{~nm}$ on a microplate reader (TriStar ${ }^{2}$ S LB 942 Multimode Reader, Berthold Technologies, Germany). The inhibition rates of the tumor cell growth were calculated by the following formula:

$$
\begin{gathered}
\text { Inhibition rate }(\%)=\left(\mathrm{OD}_{\mathrm{DMSO}}-\mathrm{OD}_{\text {compound }}\right) / \\
\mathrm{OD}_{\mathrm{DMSO}} \times 100
\end{gathered}
$$

The $\mathrm{IC}_{50}$ values were calculated using the method of log (inhibitor) vs. normalized response in the software package GraphPad Prism 5.

\section{Antibacterial Activity Assays}

The antibacterial activities were evaluated by the conventional broth dilution assay (Appendino et al., 2008). Nine marine fouling bacteria, Pseudomonas fulva, Aeromonas hydrophila, A. salmonicida, Vibrio anguillarum, V. harveyi, Photobacterium halotolerans, P. angustum, Enterobacter cloacae, and E. hormaechei, were used, and cipofloxacin was used as a positive control. The initial screening of antibacterial activity assays was tested in a 96-well plate. Each well contained $198 \mu \mathrm{l}$ tested bacterial suspension $\left(2-5 \times 10^{5} \mathrm{CFU} / \mathrm{ml}\right.$ in LB broth) and $2 \mu \mathrm{l}$ compound (final concentration was $20 \mu \mathrm{M}$ ). Three replicates were performed. The plates were incubated at $37^{\circ} \mathrm{C}$ for $24 \mathrm{~h}$, and then the OD values were tested at $600 \mathrm{~nm}$ in a microplate reader ( $\operatorname{TriStar}^{2}$ S LB 942 Multimode Reader, Berthold Technologies, Germany). The inhibitory rates were calculated according to the following formula:

$$
\begin{gathered}
\text { Inhibition rate }(\%)=\left(\mathrm{OD}_{\mathrm{DMSO}}-\mathrm{OD}_{\text {compound }}\right) / \\
\mathrm{OD}_{\mathrm{DMSO}} \times 100
\end{gathered}
$$

The MIC values of some active target compounds were evaluated using the twofold serial dilution method. The concentrations of the compounds ranged from 100 to $6.25 \mu \mathrm{M}$. The other steps were the same as in the primary screening. The MIC values were calculated using the method of log (inhibitor) vs. normalized response in the software package GraphPad Prism 5.

\section{RESULTS}

\section{Structure Elucidations of Isolated Compounds}

Pseudotremulane A (1) was obtained as a colorless oil. Its molecular formula, $\mathrm{C}_{15} \mathrm{H}_{22} \mathrm{O}_{3}$, was determined by the 
TABLE $1{ }^{1} \mathrm{H}$ NMR data of compounds $\mathbf{1 - 6}$ in $\mathrm{CDCl}_{3}$ at $600 \mathrm{MHz}$.

\begin{tabular}{|c|c|c|c|c|c|c|}
\hline No. & 1 & 2 & 3 & 4 & 5 & 6 \\
\hline 1 & & & & & $2.71, \mathrm{t}(10.5)$ & \\
\hline 3 & $3.03-2.99, \mathrm{~m}$ & $3.14-3.08, m$ & $3.15, d(12.1)$ & 3.03, d (12.2) & & 3.16 , dt $(12.1,2.8)$ \\
\hline \multirow[t]{2}{*}{4} & $2.23, \mathrm{dd}(13.5,6.1)$ & 1.95, ddt $(14.0,5.3,2.7)$ & 1.96, ddt $(13.3,5.5,2.8)$ & $2.25, \mathrm{dd}(14.1,6.2)$ & $2.47, d(16.9)$ & $2.01-1.96, \mathrm{~m}$ \\
\hline & $1.75, \mathrm{dd}(13.5,6.2)$ & 1.62, ddd (14.0, 12.5, 2.1) & 1.63, ddd $(13.3,12.1,2.1)$ & $1.88-1.78, \mathrm{~m}$ & $2.38-2.29, \mathrm{~m}$ & $1.65, \mathrm{~d}(13.2)$ \\
\hline \multirow[t]{2}{*}{5} & $2.05, \mathrm{dd}(14.2,8.5)$ & $2.03-1.98, m$ & $2.04-1.99, \mathrm{~m}$ & $2.11-2.04, \mathrm{~m}$ & $1.71-1.62, \mathrm{~m}$ & $2.05-2.02, \mathrm{~m}$ \\
\hline & 1.47, td $(14.2,6.2)$ & $1.77, \mathrm{dt}(13.5,2.7)$ & $1.81-1.79, \mathrm{~m}$ & 1.49, dt $(13.3,6.2)$ & & $1.79, \mathrm{t}(13.2)$ \\
\hline 6 & 2.11-2.07, m & $1.91-1.86, \mathrm{~m}$ & 1.91, dq $(7.0,3.0)$ & $2.17-2.11, \mathrm{~m}$ & $2.08-2.00, \mathrm{~m}$ & $1.96-1.91, \mathrm{~m}$ \\
\hline 7 & $3.10-3.03, \mathrm{~m}$ & 2.89-2.83, m & 2.98-2.92, m & 3.16 , br s & 2.08-2.00, m & $2.91-2.86, \mathrm{~m}$ \\
\hline \multirow[t]{2}{*}{8} & $1.82-1.77, \mathrm{~m}$ & $1.82-1.79, \mathrm{~m}$ & $1.58, \mathrm{t}(12.0)$ & $1.60, \mathrm{t}(12.0)$ & $1.60-1.56, \mathrm{~m}$ & $1.69, d(12.0)$ \\
\hline & $1.41, \mathrm{t}(12.5)$ & $1.40, \mathrm{dd}(13.3,10.7)$ & $1.50, \mathrm{dd}(12.0,8.4)$ & 1.42, dd $(12.0,7.3)$ & $1.53-1.50, \mathrm{~m}$ & 1.46, dd $(12.0,8.1)$ \\
\hline \multirow[t]{2}{*}{10} & $2.32, \mathrm{~d}(17.5)$ & $2.13, d(16.1)$ & $2.07, d(15.7)$ & $2.17-2.11, \mathrm{~m}$ & 3.64, dd $(10.5,6.2)$ & $3.73, \mathrm{~s}$ \\
\hline & $1.90, d(17.5)$ & $1.86-1.82, \mathrm{~m}$ & $1.85-1.81, \mathrm{~m}$ & $2.11-2.04, \mathrm{~m}$ & & \\
\hline \multirow[t]{2}{*}{11} & 4.67, d (10.3) & $4.75, d(13.2)$ & $4.75, d(13.3)$ & $4.67, \mathrm{~d}(12.0)$ & $4.91, d(17.8)$ & $5.00, d(13.6)$ \\
\hline & $4.65, d(10.3)$ & 4.69, d (13.2) & 4.68, d (13.3) & $4.62, d(12.0)$ & $4.81, d(17.8)$ & 4.88, d (13.6) \\
\hline 13 & $0.93, d(7.2)$ & $0.88, d(6.9)$ & $0.86, d(7.0)$ & $0.93, d(7.1)$ & $0.96, d(5.8)$ & $0.91, d(7.0)$ \\
\hline 14 & $1.11, \mathrm{~s}$ & $1.12, \mathrm{~s}$ & $0.92, \mathrm{~s}$ & $1.06, \mathrm{~s}$ & $0.95, \mathrm{~s}$ & $1.07, \mathrm{~s}$ \\
\hline \multirow[t]{2}{*}{15} & $3.46, d(10.6)$ & $3.30, d(10.6)$ & $3.52, \mathrm{~s}$ & $3.49, \mathrm{~s}$ & $1.07, \mathrm{~s}$ & $0.82, \mathrm{~s}$ \\
\hline & 3.39, d (10.6) & $3.26, d(10.6)$ & & & & \\
\hline
\end{tabular}

TABLE $2 \mid{ }^{13} \mathrm{C}$ NMR data of compounds $\mathbf{1 - 6}$ in $\mathrm{CDCl}_{3}$ at $150 \mathrm{MHz}$.

\begin{tabular}{|c|c|c|c|c|c|c|}
\hline No. & 1 & 2 & 3 & 4 & 5 & 6 \\
\hline 1 & 138.5, C & 138.8, C & $138.4, \mathrm{C}$ & 138.0, C & 45.0, $\mathrm{CH}$ & $140.8, \mathrm{C}$ \\
\hline 2 & 125.0, C & 125.6, C & $125.8, \mathrm{C}$ & $125.2, \mathrm{C}$ & 162.9, C & 132.6, C \\
\hline 3 & 43.56, $\mathrm{CH}$ & $44.5, \mathrm{CH}$ & $44.6, \mathrm{CH}$ & 43.6, $\mathrm{CH}$ & 128.8, C & 44.7, $\mathrm{CH}$ \\
\hline 4 & $26.5, \mathrm{CH}_{2}$ & 22.7, $\mathrm{CH}_{2}$ & 22.6, $\mathrm{CH}_{2}$ & $26.5, \mathrm{CH}_{2}$ & 20.1, $\mathrm{CH}_{2}$ & 22.2, $\mathrm{CH}_{2}$ \\
\hline 5 & $33.1, \mathrm{CH}_{2}$ & $36.9, \mathrm{CH}_{2}$ & $36.9, \mathrm{CH}_{2}$ & 33.2, $\mathrm{CH}_{2}$ & $33.5, \mathrm{CH}_{2}$ & 36.9, $\mathrm{CH}_{2}$ \\
\hline 6 & $32.7, \mathrm{CH}$ & $31.5, \mathrm{CH}$ & $31.5, \mathrm{CH}$ & $32.6, \mathrm{CH}$ & $32.7, \mathrm{CH}$ & $30.7, \mathrm{CH}$ \\
\hline 7 & $43.59, \mathrm{CH}$ & $48.4, \mathrm{CH}$ & $47.7, \mathrm{CH}$ & $43.2, \mathrm{CH}$ & $41.5, \mathrm{CH}$ & $47.5, \mathrm{CH}$ \\
\hline 8 & $40.8, \mathrm{CH}_{2}$ & $40.1, \mathrm{CH}_{2}$ & $39.7, \mathrm{CH}_{2}$ & 40.6, $\mathrm{CH}_{2}$ & 42.3, $\mathrm{CH}_{2}$ & 41.1, $\mathrm{CH}_{2}$ \\
\hline 9 & 42.6, C & $43.8, \mathrm{C}$ & $43.9, \mathrm{C}$ & $42.8, \mathrm{C}$ & 39.0, C & 42.6, C \\
\hline 10 & $41.2, \mathrm{CH}_{2}$ & 41.5, $\mathrm{CH}_{2}$ & 41.6, $\mathrm{CH} 2$ & 41.1, $\mathrm{CH}_{2}$ & 83.6, $\mathrm{CH}$ & $80.1, \mathrm{CH}$ \\
\hline 11 & 69.20, $\mathrm{CH}_{2}$ & 69.6, $\mathrm{CH}_{2}$ & 69.6, $\mathrm{CH} 2$ & $69.2, \mathrm{CH}_{2}$ & 71.1, $\mathrm{CH}_{2}$ & $68.9, \mathrm{CH} 2$ \\
\hline 12 & 177.8, C & 179.3, C & 179.3, C & 177.8, C & 175.3, C & 178.6, C \\
\hline 13 & $17.5, \mathrm{CH}_{3}$ & $12.0, \mathrm{CH}_{3}$ & $12.1, \mathrm{CH}_{3}$ & $17.7, \mathrm{CH}_{3}$ & $12.1, \mathrm{CH}_{3}$ & $12.9, \mathrm{CH}_{3}$ \\
\hline 14 & $24.3, \mathrm{CH}_{3}$ & 23.6, $\mathrm{CH}_{3}$ & $22.7, \mathrm{CH}_{3}$ & 23.2, $\mathrm{CH}_{3}$ & 23.9, $\mathrm{CH}_{3}$ & $22.1, \mathrm{CH}_{3}$ \\
\hline 15 & $69.18, \mathrm{CH}_{2}$ & $68.9, \mathrm{CH}_{2}$ & $71.2, \mathrm{CH}_{2}$ & $71.5, \mathrm{CH}_{2}$ & $29.1, \mathrm{CH}_{3}$ & $25.7, \mathrm{CH}_{3}$ \\
\hline
\end{tabular}

TABLE 3 | Cytotoxicities $\left(\mathrm{IC}_{50}, \mu \mathrm{M}\right)$ of compounds $\mathbf{8}$ and $\mathbf{9}$.

\begin{tabular}{lcc}
\hline Compounds & $\mathbf{8}$ & $\mathbf{9}$ \\
\hline MDA-MB-231 & $30 \pm 2.0$ & $27 \pm 1.7$ \\
A549 & $>40$ & $>40$ \\
HCT116 & $25 \pm 1.5$ & $23 \pm 0.93$ \\
HepG2 & $21 \pm 1.0$ & $23 \pm 1.3$ \\
PANC-1 & $>40$ & $>40$ \\
\hline
\end{tabular}

HR-APCI-MS spectrum (Supplementary Figure 7), with five degrees of unsaturation. The analysis of ${ }^{1} \mathrm{H}$ NMR and ${ }^{13} \mathrm{C}$ NMR spectra (Supplementary Figures 1, 2) combined with the HSQC spectrum (Supplementary Figure 3) of $\mathbf{1}$ indicated two methyl signals at $\delta_{H} 0.93(3 \mathrm{H}, \mathrm{d}, 7.2 \mathrm{~Hz}), \delta_{C} 17.5 ; \delta_{H} 1.11(3 \mathrm{H}, \mathrm{s}), \delta_{C}$
24.3, six methylenes, including two oxygenated methylenes at $\delta_{H}$ $3.39(1 \mathrm{H}, \mathrm{d}, 10.6 \mathrm{~Hz}), 3.46(1 \mathrm{H}, \mathrm{d}, 10.6 \mathrm{~Hz}), \delta_{C} 69.18$; $\delta_{H} 4.65(1 \mathrm{H}$, d, $10.3 \mathrm{~Hz}), 4.67(1 \mathrm{H}, \mathrm{d}, 10.3 \mathrm{~Hz}), \delta_{C} 69.20$, three methines, and four quaternary carbon signals, including two olefinic carbons at $\delta_{C} 125.0$ and $\delta_{C} 138.5$, and one ester group at $\delta_{C} 177.8$, which represented two degrees of unsaturation (Tables 1, 2). The other degrees of unsaturation revealed that there had been three rings in the structure of $\mathbf{1}$. These data suggested that $\mathbf{1}$ was tremulane-type sesquiterpenoid similar to 11,12 -epoxy-12 $\beta$ hydroxy-1-tremulen-5-one (7; Zhou et al., 2008). There had been three obvious differences between 1 and 7. The disappeared ketone carbonyl in 7 was replaced by the arisen methylene at C-5 in 1 (Tables 1, 2); this was further confirmed by the key HMBC correlation from $\mathrm{H}-13$ to $\mathrm{C}-5$ (Figure 3). The HMBC correlations from $\mathrm{H}-11$ to $\mathrm{C}-12$, and $\mathrm{H}-4$ to $\mathrm{C}-12$ indicated the 


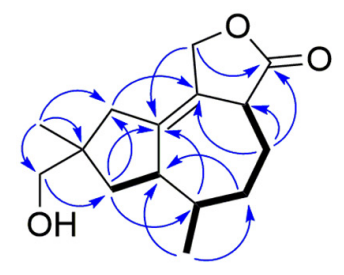

1

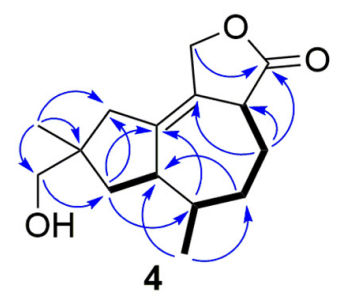

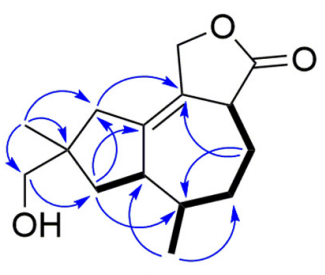

2

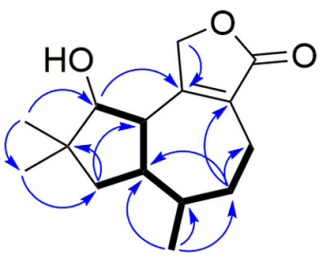

5

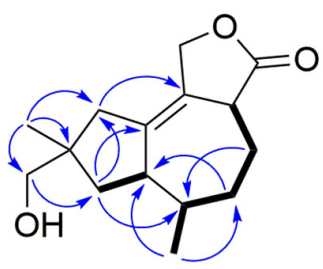

3

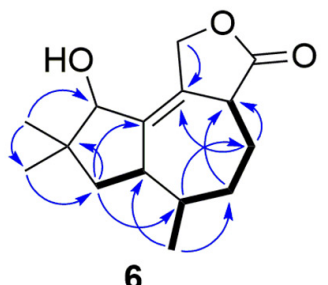

COSY $\bigcirc \mathrm{HMBC}$

FIGURE $\mathbf{3}$ | Key COSY and HMBC correlations of compounds 1-6.
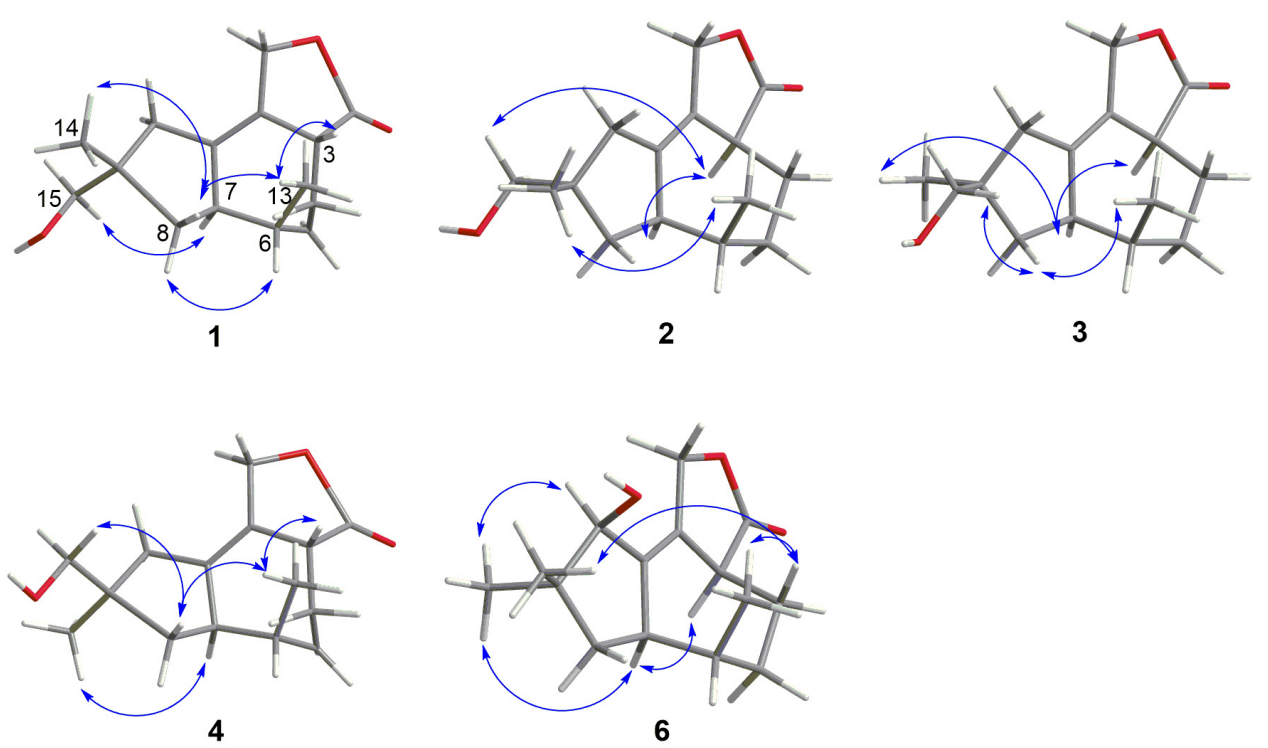

6

FIGURE $\mathbf{4}$ | Key NOESY correlations of compounds 1-4 and $\mathbf{6}$.

ester group carbon at C-12 (Figure 3). The lower field shift of C-15 data (Tables 1, 2) compared with those of 7, combined with the HMBC correlations from $\mathrm{H}-15$ to $\mathrm{C}-8$, and $\mathrm{H}-14$ to C-15 elucidated the oxidation of C-15 (Figure 3 ). Thus, the planer structure of $\mathbf{1}$ was unambiguously confirmed. The relative configurations of $\mathbf{1}$ were determined by NOESY spectra analysis (Supplementary Figure 6). The NOESY correlations between $\mathrm{H}$ 14 and $\mathrm{H}-8 \mathrm{~b}, \mathrm{H}-8 \mathrm{~b}$ and $\mathrm{H}-13$, and $\mathrm{H}-13$ and $\mathrm{H}-3$ indicated that $\mathrm{H}-14, \mathrm{H}-13$, and $\mathrm{H}-3$ were in the same orientation (Figure 4). The other orientation of $\mathrm{H}-6, \mathrm{H}-7$, and $\mathrm{H}-15$ was suggested by the NOESY cross-peaks of $\mathrm{H}-6 / \mathrm{H}-8 \mathrm{a}$ and $\mathrm{H}-7 / \mathrm{H}-15$ (Figure 4). Therefore, the relative configurations of $\mathbf{1}$ were assigned as $3 R^{*}, 6 R^{*}, 7 R^{*}, 9 S^{*}$.
Pseudotremulane B (2) was gained as a colorless oil, with the molecular formula of $\mathrm{C}_{15} \mathrm{H}_{22} \mathrm{O}_{3}$ determined by HR-APCIMS indicating five degrees of unsaturation and had the same molecular formula as $\mathbf{1}$ (Supplementary Figure 14). The ${ }^{1} \mathrm{H}$ and ${ }^{13} \mathrm{C}$ NMR data of 2 were very similar to those of 1 (Tables 1, 2). The downfield shift of C-2, C-3, C-5, C-7, C-9, C-11, and C-12 and the high-field shift of C-4, C-6, C-8, C-13, and C-14 in ${ }^{13} \mathrm{C}$ NMR suggested the difference configurations between 1 and 2 . The NOESY cross-peaks of $\mathrm{H}-15 / \mathrm{H}-3$ and $\mathrm{H}-3 / \mathrm{H}-7$ declared that $\mathrm{H}-3, \mathrm{H}-7$, and $\mathrm{H}-15$ were in the same face (Figure 4). The NOESY correlation of $\mathrm{H}-13$ and $\mathrm{H}-14$ indicated that $\mathrm{H}-13$ and $\mathrm{H}-14$ were in another face. Therefore, the relative configurations of 2 were assigned as $3 S^{*}, 6 R^{*}, 7 R^{*}, 9 S^{*}$. 
Pseudotremulane C (3) was acquired as a colorless oil. The HR-APCI-MS of 3 exhibited the same molecular formula with 1 and 2 (Supplementary Figure 21). The strong similar ${ }^{1} \mathrm{H}$ and ${ }^{13} \mathrm{C}$ NMR data between 2 and 3 (Tables 1, 2) suggested that they shared the same planer structures. The high-field shift of C-14 and the downfield shift of C-15 (Table 2) revealed the difference configurations of C-9 of 2 and 3. The $\alpha$-orientation of $\mathrm{H}-3, \mathrm{H}-7$, and $\mathrm{H}-14$ was determined by the NOESY correlations of $\mathrm{H}-3 / \mathrm{H}-$ 7 and $\mathrm{H}-7 / \mathrm{H}-14$ (Figure 4). The $\beta$-orientation of $\mathrm{H}-13$ and $\mathrm{H}-15$ was determined by the NOESY cross-peaks of $\mathrm{H}-13 / \mathrm{H}-8 \mathrm{a}$ and $\mathrm{H}-$ $8 \mathrm{a} / \mathrm{H}-15$ (Figure 4). Compounds 2 and 3 were a pair of epimeride at the location of C-9.

Pseudotremulane D (4) was obtained as a colorless oil, with the same molecular formula with 1-3, according the analysis of its HR-APCI-MS spectrum (Supplementary Figure 28). Careful analysis of the ${ }^{1} \mathrm{H}$ and ${ }^{13} \mathrm{C}$ NMR data of $\mathbf{1}$ and $\mathbf{4}$ indicated that they had the same planer structures. The difference configurations of C-9 of $\mathbf{1}$ and $\mathbf{4}$ were determined by the highfield shift of C-14 and the downfield shift of C-15 (Table 2). The NOESY correlations of $\mathrm{H}-3 / \mathrm{H}-13, \mathrm{H}-13 / \mathrm{H}-8 \mathrm{a}$, and $\mathrm{H}-8 \mathrm{a} / \mathrm{H}-15$ (Figure 4) revealed the $\beta$-orientation of $\mathrm{H}-3, \mathrm{H}-13$, and $\mathrm{H}-15$. The $\alpha$-orientation of $\mathrm{H}-7$ and $\mathrm{H}-14$ was proved by the NOESY cross-peak of H-7/H-14 (Figure 4). Compounds 1 and 4 were a pair of epimeride at the location of C-9.

Pseudotremulane E (5) was obtained as a colorless oil. Its molecular formula was the same as $\mathbf{1 - 4}$, as suggested by HRAPCI-MS (Supplementary Figure 35). The NMR spectra of 5 revealed the presence of three methyls, four methylenes (one oxygenated), four methines (one oxygenated), and four quaternary carbons (one ester group carbon, two olefinic, and one $\mathrm{sp}^{3}$ quaternary carbon; Supplementary Figures 29-31). These characteristic NMR spectroscopic data of $\mathbf{5}$ showed similarities with those of 11,12-epoxy-12 $\beta$-hydroxy-1-tremulen-5-one (7; Zhou et al., 2008). Compared with 7, the disappeared ketone at C5 was substituted by methylene $\left[\delta_{H} 1.71-1.62(2 \mathrm{H}, \mathrm{m}), \delta_{C} 33.5\right]$ in 5 (Tables 1,2 ), elucidated by the ${ }^{1} \mathrm{H}^{1}{ }^{1} \mathrm{H}$ COSY correlations of $\mathrm{H}-6 / \mathrm{H}-5$ and $\mathrm{H}-5 / \mathrm{H}-4$, and further confirmed by the HMBC correlations from $\mathrm{H}-13$ to $\mathrm{C}-5$, and $\mathrm{H}-5$ to $\mathrm{C}-3, \mathrm{C}-4$, and C-7 (Figure 3). The position of the double bond was changed from $\mathrm{C}-1 / \mathrm{C}-2$ in 7 into C-2/C-3 in 5 , proved by the ${ }^{1} \mathrm{H}-{ }^{1} \mathrm{H}$ COSY crosspeak of $\mathrm{H}-1 / \mathrm{H}-7$ and the $\mathrm{HMBC}$ signals of $\mathrm{H}-10 / \mathrm{C}-2, \mathrm{H}-11 / \mathrm{C}-2$, and $\mathrm{H}-5 / \mathrm{C}-3$ (Figure 3 ). The absence of carbonyl carbon $\left(\delta_{C}\right.$ 175.3) in 5 and the disappeared oxygenated methine at C-12 in 7 , combined with the molecular formula of 5 , revealed that there had been an ester group at C-12 in 5. The large coupling constants of $\mathrm{H}-1 / \mathrm{H}-10(J=11.0 \mathrm{~Hz})$ and $\mathrm{H}-1 / \mathrm{H}-7(J=11.0 \mathrm{~Hz})$ revealed the $\beta$-orientation of $\mathrm{H}-1$ and the $\alpha$-orientation of $\mathrm{H}-7$ and $\mathrm{H}-10$ (Table 1). The overlapped ${ }^{1} \mathrm{H}$ NMR signals of $\mathrm{H}-6 / \mathrm{H}-7$ and $\mathrm{H}-$ $13 / \mathrm{H}-14$ increased the difficulties to decide the configurations of 5 (Table 1). However, based on biogenetic considerations, H-13 was proposed to have $\beta$-orientation be the same with 1-6.

Pseudotremulane F (6) was isolated as a colorless oil. The same molecular formula of $\mathrm{C}_{15} \mathrm{H}_{22} \mathrm{O}_{3}$ was determined by the HR-APCI-MS spectrum (Supplementary Figure 42). The three methyls, four methylenes (one oxygenated), four methines (one oxygenated), and four quaternary carbons (one ester group carbon, two olefinic, and one $\mathrm{sp}^{3}$ quaternary carbon) exhibited

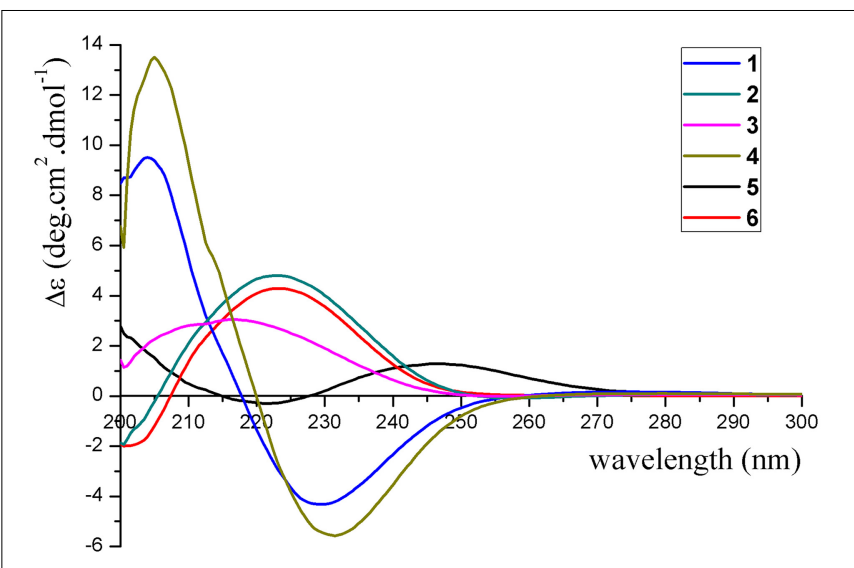

FIGURE 5 | Experimental ECD spectra of compounds 1-6.

in the NMR spectra (Supplementary Figures 29-31), indicating the similar structures of $\mathbf{6}$ and $\mathbf{5}$. The most obvious differences of ${ }^{13} \mathrm{C}$ NMR data between $\mathbf{6}$ and 5 were the downfield shift of C-1 $\left(\delta_{C} 140.8\right.$ in $6 v s \delta_{C} 45.0$ in 5) and the high-field shift of C-2 $\left(\delta_{C}\right.$ 132.6 in 6 vs $\delta_{C} 162.9$ in 5) and C-3 ( $\delta_{C} 44.7$ in 6 vs $\delta_{C} 128.8$ in 5; Table 2), elucidating that the olefinic bond location was changed from C-2/C-3 in 5 into $\mathrm{C}-1 / \mathrm{C}-2$ in $\mathbf{6}$. This was further confirmed by the HMBC correlations from $\mathrm{H}-11$ to $\mathrm{C}-2, \mathrm{H}-4$ to $\mathrm{C}-2$, and $\mathrm{H}-8$ to $\mathrm{C}-1$ (Figure 3 ). The $\beta$-orientation of $\mathrm{H}-13$ and $\mathrm{H}-14$ was revealed by the NOESY cross-peaks of $\mathrm{H}-13 / \mathrm{H}-4 \mathrm{~b}$ and $\mathrm{H}-4 \mathrm{~b} / \mathrm{H}-14$, and the $\alpha$-orientation of $\mathrm{H}-3, \mathrm{H}-7, \mathrm{H}-15$, and $\mathrm{H}-10$ was suggested by the NOESY correlations of $\mathrm{H}-3 / \mathrm{H}-7, \mathrm{H}-7 / \mathrm{H}-15$, and $\mathrm{H}-15 / \mathrm{H}-10$ (Figure 4).

The absolute configurations of 1-6 were determined by their ECD spectra (Figure 5) and were further confirmed by ECD calculations. The experimental ECD spectrum of 1 exhibited a negative cotton effect at $230 \mathrm{~nm}$. According to the $\pi-\pi^{*} \mathrm{CD}$ octant rule for olefins (Guo et al., 2016), the negative cotton effect at $230 \mathrm{~nm}$ was caused by ester carbonyl (C-12) and oxymethene (C-11) lying in the negative contribution region (Figure 5). Combined with the relative configuration conclusions, the absolute configurations of $\mathbf{1}$ were established as $3 R, 6 R, 7 R, 9 S$, and named as pseudotremulane A. The similar ECD spectra of 4 and 5 with the negative cotton effects at 232 and $222 \mathrm{~nm}$ (Figure 5), respectively, indicated the absolute configurations of $3 R, 6 R, 7 R, 9 R-4$ and $1 S, 6 R, 7 R, 10 S-5$. The positive cotton effects of the ECD spectra of compounds 2 (223 nm), $3(217 \mathrm{~nm})$, and 6 $(223 \mathrm{~nm})$ elucidated the absolute configurations of $3 S, 6 R, 7 R, 9 S-$ 2, $3 S, 6 R, 7 R, 9 R-\mathbf{3}$, and $3 S, 6 R, 7 R, 10 R-6$ (Figure 5). Thus, the structures compounds $2-6$ were completely confirmed and named as pseudotremulanes B-F, respectively.

To further conform these results, the theoretical ECDs of compounds 1-6 (Figure 6) were calculated to compare with their experimental ECD spectra (Mazzeo et al., 2013; Cao et al., 2020). The MMFF94S method was used to conformational searches of 1a-6a to obtain the lowest energy conformers with relative energies between 0 and $10 \mathrm{kcal} / \mathrm{mol}$. Gaussian 09 package was used to optimize the searched conformations. The first optimization was set at the gas-phase RB3LYP/6-31G(d) level to 

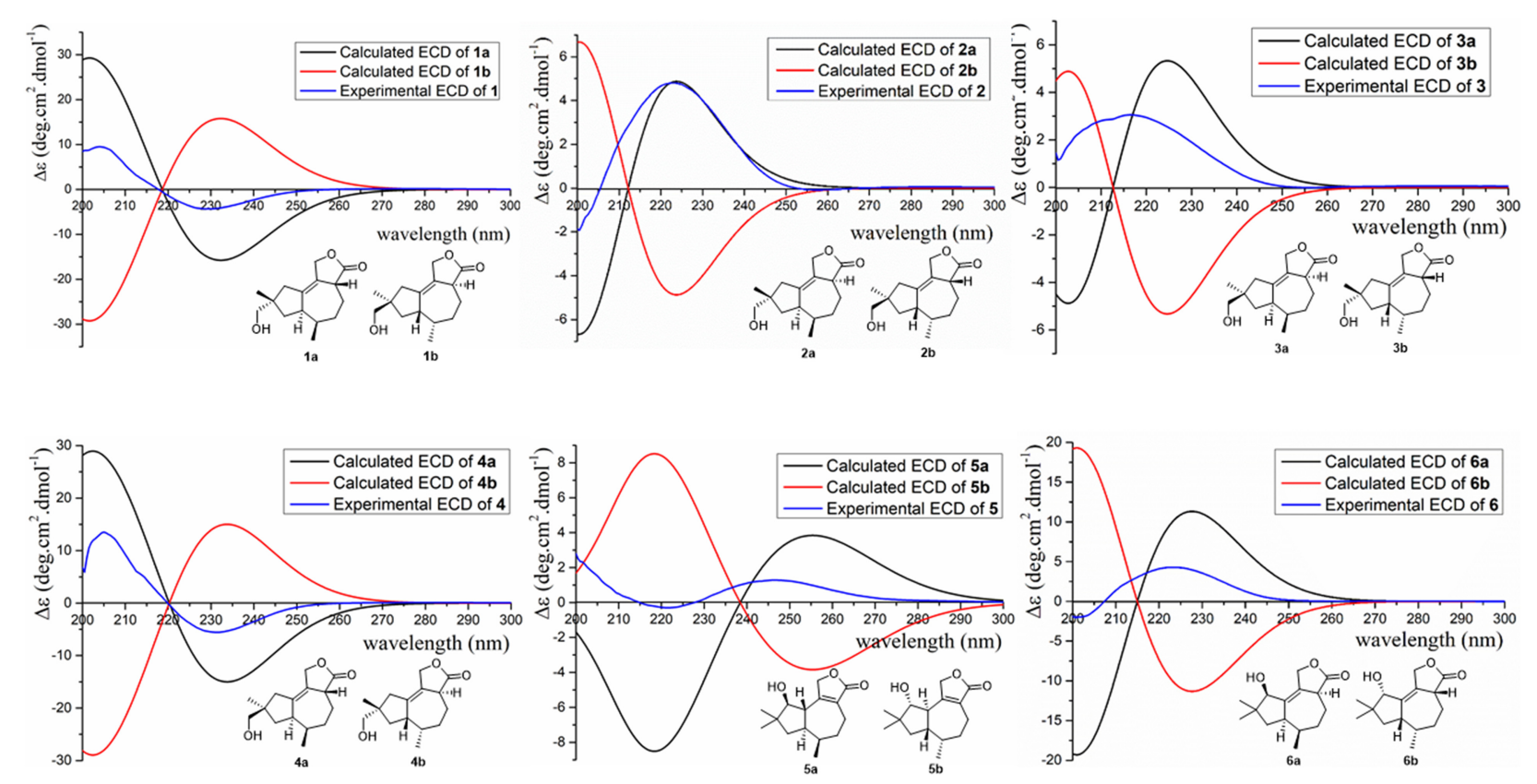

FIGURE 6 | Experimental and calculated ECD of compounds 1-6.

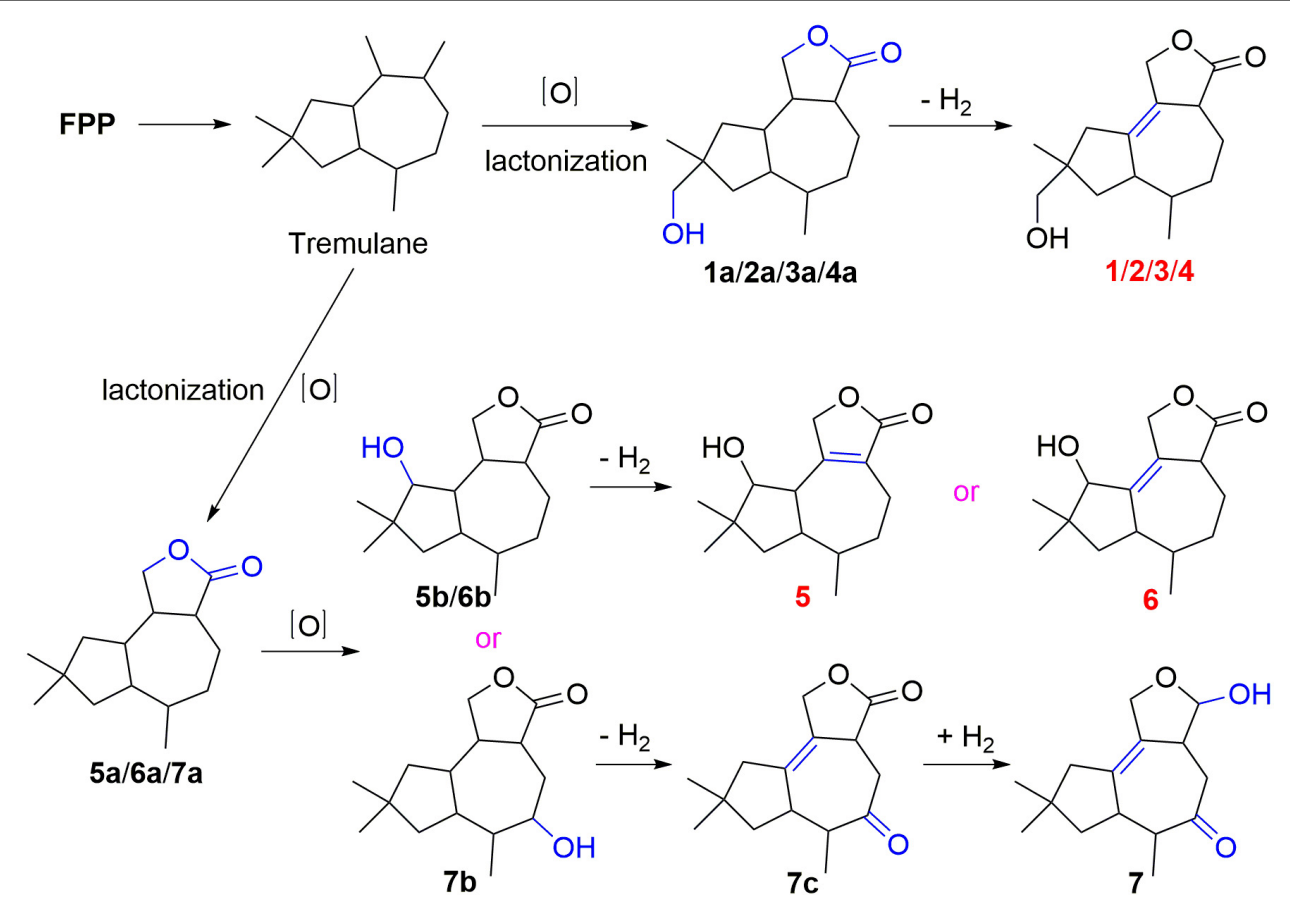

FIGURE 7 | Proposed biosynthetic pathway for 1-7.

get preferential conformations with the relative energies less than $2.5 \mathrm{kcal} / \mathrm{mol}$. Then the conformers were optimized again at the set of gas-phase B3LYP/6-311 + G(d). The total 60 electronic excited states were calculated at the set of gas-phase RB3LYP/6$311++\mathrm{G}(2 \mathrm{~d}, \mathrm{p})$. Boltzmann statistics were used to simulate
ECD with a standard deviation of $\sigma 0.4 \mathrm{eV}$. The theoretical ECD spectra of $\mathbf{1 b}-\mathbf{6} \mathbf{b}$ were obtained by directly reversing the spectra of 1a-6a, respectively. The results exhibited that the experimental ECDs of 1-6 were matched well with the calculated ECDs of 1a6a, respectively, which further verified the absolute structures of 


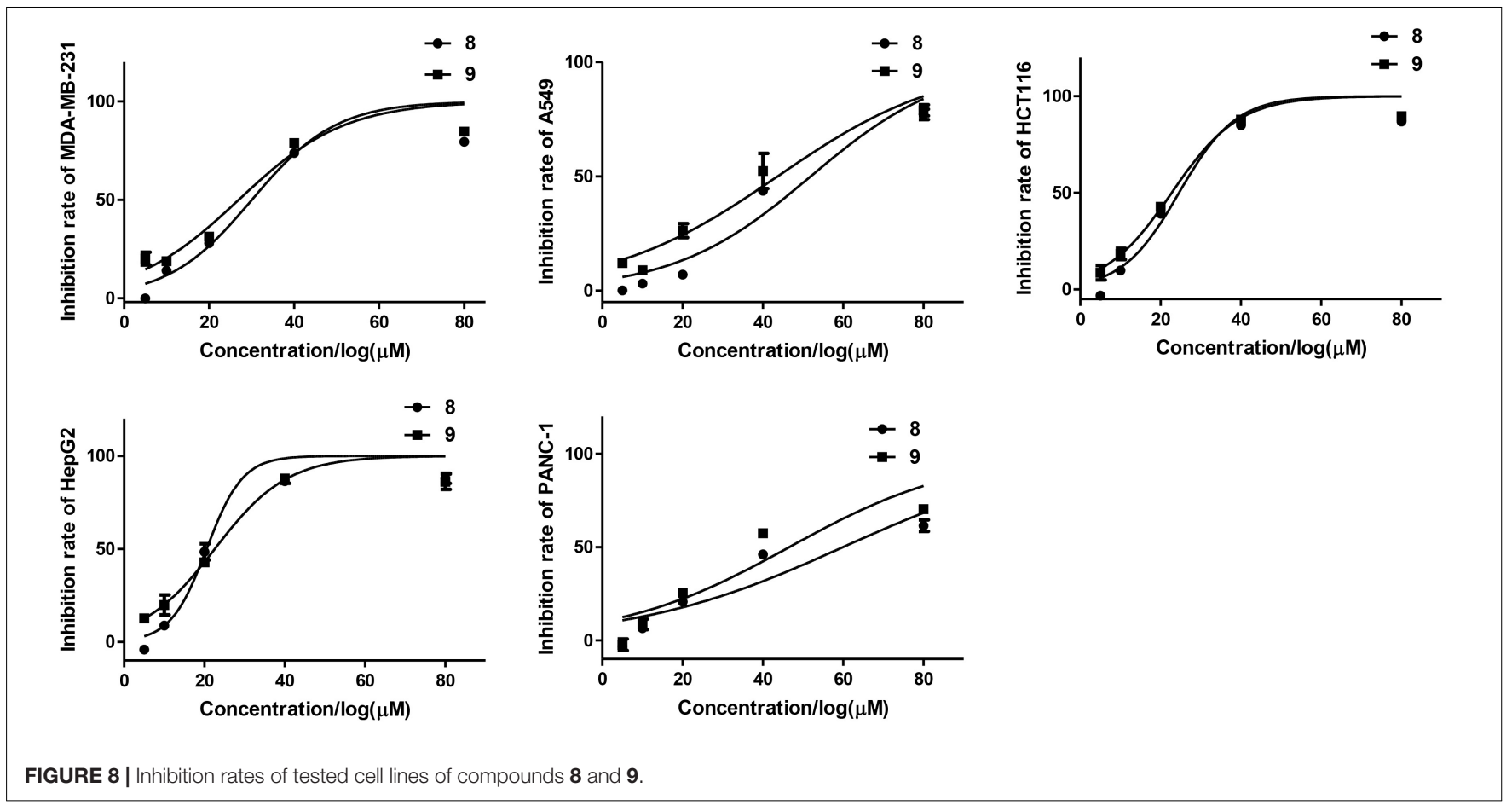

1-6 (Figure 6). Interestingly, compounds $1 / 2,3 / 4,1 / 4$, and $2 / 3$ were identified as four pairs of epimeride at the locations of $\mathrm{C}-3$, C-3, C-9, and C-9, respectively.

The structures of 7-12 were determined as 11,12-epoxy-12 $\beta$ hydroxy-1-tremulen-5-one (Zhou et al., 2008), ganodermasides A, B, and D (Weng et al., 2010, 2011), ergosterol (Feng et al., 2010), and dankasterone B (Amagata et al., 2007), respectively, by comparing their NMR data with those in the literature.

\section{Proposed Biosynthetic Pathway for 1-7}

Compounds 1-7 could derive from tremulane, a 5/7 endocyclic system sesquiterpenoid (Figure 7; He et al., 2020; Wang et al., 2020). As exhibited in Figure 7, compounds 1-7 could be obtained after a series of oxidation, lactonization, dehydrogenation, and revivification of tremulane. The intermediate products $\mathbf{1 a} / \mathbf{2} \mathbf{a} / \mathbf{3} \mathbf{a} / \mathbf{4 a}$ were obtained after the oxidation of tremulane at C-11, C-12, and C-15 and lactonization at $\mathrm{C}-11$ and $\mathrm{C}-12$. Then the dehydrogenation of the intermediate products at C-1 and C-2 acquired the compounds 1-4. Similarly, compounds 5, 6, and 7c were gained from tremulane after the reactions of oxidation, lactonization, and dehydrogenation. Compound 7 was obtained from the revivification of $7 c$.

\section{Bioactivity Evaluations of Isolated Compounds}

All the isolated compounds (1-12) were evaluated for their cytotoxic activities against five human cancer cell lines (MDAMB-231, HCT116, HepG2, A549, and PANC-1). Compounds 8 and 9 exhibited cytotoxicities against MDA-MB-231, HCT116, and HepG2 cell lines with the $\mathrm{IC}_{50}$ values ranging from 21 to $30 \mu \mathrm{M}$ (Table 3 and Figure 8).

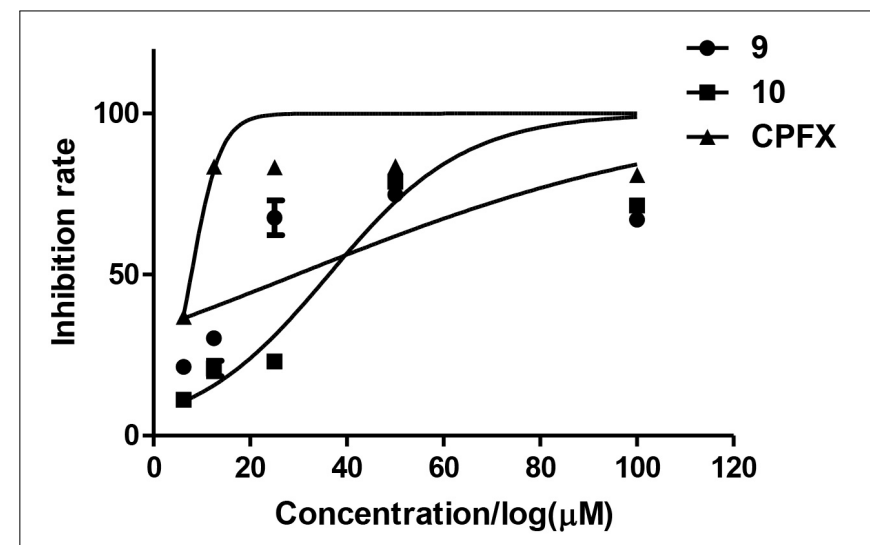

FIGURE 9 | Inhibition rates of $A$. salmonicida of compounds $\mathbf{9}$ and $\mathbf{1 0 .}$

The antibacterial activities of the isolated compounds (1-12) were also evaluated against nine marine fouling bacteria $P$. fulva, A. hydrophila, A. salmonicida, $V$. anguillarum, $V$. harveyi, P. halotolerans, P. angustum, E. cloacae, and E. hormaechei. Compounds $\mathbf{9}$ and $\mathbf{1 0}$ showed antibacterial activities against marine fouling bacteria A. salmonicida with the MIC values of 30 and $36 \mu \mathrm{M}$, respectively (Figure 9). The MIC value of the positive control ciprofloxacin (CPFX) was 7.8 $\mu \mathrm{M}$ (Figure 9).

\section{CONCLUSION}

In summary, six new tremulane sesquiterpenoids, pseudotremulanes A-F (1-6), together with one known analog, 11,12-epoxy-12 $\beta$-hydroxy-1-tremulen-5-one (7), and 
five known steroids, ganodermasides A (8), B (9), and D (10), ergosterol (11), and dankasterone B (12), were isolated from the Antarctic-derived fungus Pseudogymnoascus sp. HSX2\#-11. Compounds 1-7 were proved to be isomeride structures with the same chemical formula. Compounds 1 and 2, 3 and 4, 1 and $\mathbf{4}$, and $\mathbf{2}$ and $\mathbf{3}$ were identified as four pairs of epimeride at the locations of C-3, C-3, C-9, and C-9, respectively. Compounds 8 and 9 exhibited cytotoxicities against MDA-MB-231, HCT116, and HepG2 cell lines. Compounds $\mathbf{9}$ and $\mathbf{1 0}$ showed antibacterial activities against marine fouling bacteria $A$. salmonicida. This is the first time to discover terpenoids and steroids from the fungal genus Pseudogymnoascus. Our chemical investigation of the Antarctic fungus Pseudogymnoascus sp. HSX2\#-11 enriches the chemical diversity of this fungal species.

\section{DISCUSSION}

The genus Pseudogymnoascus as a kind of psychrophilic pathogenic fungi is widely distributed in Antarctica (Rosa et al., 2020; Santos et al., 2020; Martorell et al., 2021). Pseudogymnoascus can be one of the antagonistic fungi against potato scab pathogens from potato field soils, which could be used as potential agents to control potato scab disease (Tagawa et al., 2010). Pseudogymnoascus spp. has been certified to be one of the predominant microbial colonizers in the root endosphere and rhizosphere of turfgrass systems (Xia et al., 2021). The extracts of some Pseudogymnoascus strains exhibit potent bioactivities, such as antimicrobial, herbicidal, and antitumoral activities (Henríquez et al., 2014; Gonçalves et al., 2015; Gomes et al., 2018; Ferrarezi et al., 2019). To the best of our knowledge, only 22 natural products, including 6 new compounds, were discovered from Pseudogymnoascus up to now (Figueroa et al., 2015; Guo et al., 2019; Fujita et al., 2021; Shi et al., 2021). More than $70 \%$ of the previously isolated structures belong to polyketides; others are alkaloids (13.6\%), benzene derivative $(9.1 \%)$, and fatty acid (4.5\%). Our research isolated 12 natural products (1-12), including 6 new compounds (1-6), from the fungus Pseudogymnoascus 2\#-11. All of the isolated compounds are first obtained from the genus Pseudogymnoascus. This is the first time to discover terpenoids and steroids from the genus Pseudogymnoascus. The whole number of the fungal strain secondary metabolites increased by $35 \%$, and the number of their new compounds is doubled. This greatly enriches the number and diversity of natural products of the genus Pseudogymnoascus. Except for antimicrobial activities of some of the previously obtained polyketides (Figueroa et al., 2015; Fujita et al., 2021; Shi et al., 2021), no other activities were found in Pseudogymnoascus in previous studies. This study is the first to identify secondary metabolites with cytotoxic activities (8 and 9) in Pseudogymnoascus.

The isolated new sesquiterpenoids (1-6), with characteristic structures of $5 / 7$ fused bicyclic system, belong to the family of tremulanes. Tremulane derivatives have been found from cultures of Phellinus tremulae (Ayer and Cruz, 1993), P. igniarius (Liu et al., 2007; Wu et al., 2020), Conocybe siliginea (Zhou et al., 2008; Wu et al., 2010; He et al., 2020), Huperzia serrata
(Ying et al., 2013), Flavodon flavus (Isaka et al., 2016), Coriolopsis sp. (Chen et al., 2017), Colletotrichum capsici (Wang et al., 2017), I. lacteus (Chen et al., 2018, 2020; Ding et al., 2018, 2019, 2020a,b; Zhou et al., 2018; Duan et al., 2019; Wu et al., 2019; Shi et al., 2020; Sun C.-T. et al., 2020; Wang et al., 2020), and Gymnopilus junonius (Lee et al., 2020). This is the first time to find tremulane derivatives from Pseudogymnoascus.

\section{DATA AVAILABILITY STATEMENT}

The datasets presented in this study can be found in online repositories. The names of the repository/repositories and accession number(s) can be found in the article/ Supplementary Material.

\section{AUTHOR CONTRIBUTIONS}

TS contributed to experimental design and operation, data analysis, and manuscript preparation. X-QL contributed to manuscript revision. LZ supported the sample of the Antarctic soil. Y-HZ contributed to ECD calculations. J-JD contributed to activity evaluations. E-LS contributed to software drawing guidance. Y-YY, Y-TZ, and W-PH contributed to activity evaluations. D-YS was the project leader organizing and guiding the experiments. All authors contributed to the article and approved the submitted version.

\section{FUNDING}

This work was supported by the Natural Science Foundation of Shandong Province of China (No. ZR2020QD111); the China Postdoctoral Science Foundation (No. 2019M662378); the National Program for Support of Top-notch Young Professionals; the Fund of Taishan Scholar Project; The Shandong Provincial Natural Science Foundation for Distinguished Young Scholars (JQ201722); the Qingdao Science and Technology Benefit People Demonstration Guide Special Project (20-3-420-nsh); and the Fundamental Research Funds of Shandong University (2020GN033).

\section{ACKNOWLEDGMENTS}

We would like to thank Antarctic Great Wall National Observation and Research Station of Polar Ecosystem for sample collection; Jing-Yao Qu, Jing Zhu, and Zhi-Feng Li in MS, and Hai-Yan Sui in NMR for help and guidance from State Key Laboratory of Microbial Technology of Shandong University.

\section{SUPPLEMENTARY MATERIAL}

The Supplementary Material for this article can be found online at: https://www.frontiersin.org/articles/10.3389/fmicb.2021. 688202/full\#supplementary-material 


\section{REFERENCES}

Amagata, T., Tanaka, M., Yamada, T., Doi, M., Minoura, K., Ohishi, H., et al. (2007). Variation in cytostatic constituents of a sponge-derived Gymnascella dankaliensis by manipulating the carbon source. J. Nat. Prod. 70, 1731-1740. doi: $10.1021 / \mathrm{np} 070165 \mathrm{~m}$

Appendino, G., Gibbons, S., Giana, A., Pagani, A., Grassi, G., Stavri, M., et al. (2008). Antibacterial cannabinoids from Cannabis sativa: a structure-activity study. J. Nat. Prod. 71, 1427-1430.

Ayer, W. A., and Cruz, E. R. (1993). The tremulanes, a new group of sesquiterpenes from the aspen rotting fungus Phellinus tremulae. J. Org. Chem. 58, 7529-7534.

Cao, F., Meng, Z.-H., Wang, P., Luo, D.-Q., and Zhu, H.-J. (2020). Dipleosporalones $\mathrm{A}$ and $\mathrm{B}$, dimeric azaphilones from a marine-derived Pleosporales sp. fungus. J. Nat. Prod. 83, 1283-1287.

Chen, H.-P., Ji, X., Li, Z.-H., Feng, T., and Liu, J.-K. (2020). Irlactane and tremulane sesquiterpenes from the cultures of the medicinal fungus Irpex lacteus HFG1102. Nat. Prod. Bioprospect. 10, 89-100. doi: 10.1007/s13659-02000239-z

Chen, H.-P., Zhao, Z.-Z., Li, Z.-H., Feng, T., and Liu, J.-K. (2018). Seco-tremulane sesquiterpenoids from the cultures of the medicinal Fungus Irpex lacteus HFG1102. Nat. Prod. Bioprospect. 8, 113-119. doi: 10.1007/s13659-018-0157-y

Chen, L.-L., Kong, F.-D., Wang, P., Yuan, J.-Z., Guo, Z.-K., Wang, H., et al. (2017). Two new tremulane sesquiterpenes from a mangrove endophytic fungus. Coriolopsis sp. J5. Chin. Chem. Lett. 28, 222-225. doi: 10.1016/j.cclet.2016.07. 019

Cong, B., Yin, X., Deng, A., Shen, J., and Yang, H. (2020). Diversity of cultivable microbes from soil of the Fildes Peninsula, Antarctica, and their potential application. Front. Microbiol. 11:570836. doi: 10.3389/fmicb.2020.570836

Ding, J.-H., Li, Z.-H., Feng, T., and Liu, J.-K. (2018). Tremulane sesquiterpenes from cultures of the basidiomycete Irpex lacteus. Fitoterapia 125, 245-248. doi: 10.1016/j.fitote.2017.12.001

Ding, J.-H., Li, Z.-H., Feng, T., and Liu, J.-K. (2019). A new tremulane sesquiterpenoid from the fungus Irpex lacteus. Nat. Prod. Res. 33, 316-320. doi: 10.1080/14786419.2018.1448816

Ding, J.-H., Li, Z.-H., Feng, T., and Liu, J.-K. (2020a). A sesquiterpene lactone from Irpex lacteus. Chem. Nat. Compd. 56, 403-405. doi: 10.1007/s10600-020-03 047-6

Ding, J.-H., Li, Z.-H., Feng, T., and Liu, J.-K. (2020b). Two new sesquiterpenes from cultures of the fungus Irpex lacteus. J. Asian Nat. Prod. Res. 23, 348-352. doi: 10.1080/10286020.2020.1737857

Duan, X.-X., Qin, D., Song, H.-C., Gao, T.-C., Zuo, S.-H., Yan, X., et al. (2019). Irpexlacte A-D, four new bioactive metabolites of endophytic fungus Irpex lacteus DR10-1 from the waterlogging tolerant plant Distylium chinense. Phytochem. Lett. 32, 151-156. doi: 10.1016/j.phytol.2019.06.001

Feng, N., Zhang, J., Tang, Q., Hao, R., Liu, Y., Yang, Y., et al. (2010). Steroids from fruiting bodies of Coprinus comatus and their inhibition to tumor cell proliferation. Junwu Xuebao 29, 249-253.

Ferrarezi, J. H., Dos Santos, J. A., Sette, L. D., Ferreira, H., and Sass, D. C. (2019). Anti-Xanthomonas activity of Antarctic fungi crude extracts. Afr. J. Biotechnol. 18, 713-718. doi: 10.5897/ajb2019.16886

Figueroa, L., Jiménez, C., Rodríguez, J., Areche, C., Chávez, R., Henríquez, M., et al. (2015). 3-Nitroasterric acid derivatives from an Antarctic sponge-derived Pseudogymnoascus sp. fungus. J. Nat. Prod. 78, 919-923.

Fujita, K., Ikuta, M., Nishimura, S., Sugiyama, R., Yoshimura, A., and Kakeya, H. (2021). Amphiol, an antifungal fungal pigment from Pseudogymnoascus sp. PF1464. . J. Nat. Prod. 84, 986-992. doi: 10.1021/acs.jnatprod.0c01010

Gomes, E. C. Q., Godinho, V. M., Silva, D. A. S., de Paula, M. T. R., Vitoreli, G. A., Zani, C. L., et al. (2018). Cultivable fungi present in Antarctic soils: taxonomy, phylogeny, diversity, and bioprospecting of antiparasitic and herbicidal metabolites. Extremophiles 22, 381-393. doi: 10.1007/s00792-0181003-1

Gonçalves, V. N., Carvalho, C. R., Johann, S., Mendes, G., Alves, T. M. A., and Zani, C. L. (2015). Antibacterial, antifungal and antiprotozoal activities of fungal communities present in different substrates from Antarctica. Polar Biol. 38, 1143-1152. doi: 10.1007/s00300-015-1672-5

Guo, Y.-Z., Wei, Q., Gao, J., Liu, B.-Y., Zhang, T., Hua, H.-M., et al. (2019). Metabolites of the psychrophilic fungus Pseudogymnoascus pannorum. Nat. Prod. Res. Dev. 31, 446-449.
Guo, Z., Li, X., Zhang, L., Feng, Z., Deng, Z., He, H., et al. (2016). Cytotoxic tremulanes and 5,6-secotremulanes, four new sesquiterpenoids from a plantassociated fungus X1-2. Nat. Prod. Res. 30, 2582-2589. doi: 10.1080/14786419. 2015.1135140

He, J., Pu, C.-J., Wang, M., Li, Z.-H., Feng, T., Zhao, D.-K., et al. (2020). Conosiligins A-D, ring-rearranged tremulane sesquiterpenoids from Conocybe siliginea. J. Nat. Prod. 83, 2743-2748. doi: 10.1021/acs.jnatprod.0c00681

Henríquez, M., Vergara, K., Norambuena, J., Beiza, A., Maza, F., Ubilla, P., et al. (2014). Diversity of cultivable fungi associated with Antarctic marine sponges and screening for their antimicrobial, antitumoral and antioxidant potential. World J. Microbiol. Biotechnol. 30, 65-76. doi: 10.1007/s11274-013-1418-x

Isaka, M., Palasarn, S., Supothina, S., Srichomthong, K., and Choeyklin, R. (2016). Seco-tremulanes from cultures of the basidiomycete Flavodon flavus BCC 17421. Helv. Chim. Acta 99, 232-236. doi: 10.1002/hlca.201500249

Kwon, J., Lee, H., Ko, W., Kim, D. C., Kim, K. W., Kwon, H. C., et al. (2017). Chemical constituents isolated from Antarctic marine-derived Aspergillus sp. SF-5976 and their anti-inflammatory effects in LPS-stimulated RAW 264.7 and BV2 cells. Tetrahedron 73, 3905-3912.

Lee, S., Ryoo, R., Choi, J. H., Kim, J.-H., Kim, S.-H., and Kim, K. H. (2020). Trichothecene and tremulane sesquiterpenes from a hallucinogenic mushroom Gymnopilus junonius and their cytotoxicity. Arch. Pharm. Res. 43, 214-223. doi: 10.1007/s12272-020-01213-6

Liu, D. Z., Wang, F., and Liu, J. K. (2007). Sesquiterpenes from cultures of the basidiomycete Conocybe siliginea. J. Nat. Prod. 70, 1503-1506.

Loperena, L., Soria, V., Varela, H., Lupo, S., Bergalli, A., Guigou, M., et al. (2012). Extracellular enzymes produced by microorganisms isolated from maritime Antarctica. World J. Microbiol. Biotechnol. 28, 2249-2256. doi: 10.1007/s11274012-1032-3

Martorell, M. M., Lannert, M., Matula, C. V., Quartino, M. L., de Figueroa, L. I. C., MacCormack, W. P., et al. (2021). Studies toward the comprehension of fungal-macroalgae interaction in cold marine regions from a biotechnological perspective. Fungal Biol. 125, 218-230. doi: 10.1016/j.funbio.2020.11.003

Mazzeo, G., Santoro, E., Andolfi, A., Cimmino, A., Troselj, P., Petrovic, A. G., et al. (2013). Absolute configurations of fungal and plant metabolites by chiroptical methods. ORD, ECD, and VCD studies on phyllostin, scytolide, and oxysporone. J. Nat. Prod. 76, 588-599.

Poveda, G., Gil-Durán, C., Vaca, I., Levicán, G., and Chávez, R. (2018). Coldactive pectinolytic activity produced by flamentous fungi associated with Antarctic marine sponges. Biol. Res. 51:28. doi: 10.1186/s40659-0180177-4

Rosa, L. H., Pinto, O. H. B., Convey, P., Carvalho-Silva, M., Rosa, C. A., and Camara, P. E. A. S. (2020). DNA metabarcoding to assess the diversity of airborne fungi present over Keller Peninsula, King George Island, Antarctica. Microb. Ecol. doi: 10.1007/s00248-020-01627-1 [Online ahead of Print].

Rusman, Y., Held, B. W., Blanchette, R. A., He, Y., and Salomon, C. E. (2018). Cadopherone and colomitide polyketides from Cadophora wood-rot fungi associated with historic expedition huts in Antarctica. Phytochemistry 148:1.

Santos, J. A. D., Meyer, E., and Sette, L. D. (2020). Fungal community in antarctic soil along the retreating Collins Glacier (Fildes Peninsula, King George Island). Microorganisms 8:1145. doi: 10.3390/microorganisms8081145

Shi, L.-J., Wu, Y.-M., Yang, X.-Q., Xu, T.-T., Yang, S., Wang, X.-Y., et al. (2020). The cocultured Nigrospora oryzae and Collectotrichum gloeosporioides, Irpex lacteus, and the plant host Dendrobium officinale bidirectionally regulate the production of phytotoxins by anti-phytopathogenic metabolites. J. Nat. Prod. 83, 1374-1382. doi: 10.1021/acs.jnatprod.0c00036

Shi, T., Yu, Y.-Y., Dai, J.-J., Zhang, Y.-T., Hu, W.-P., Zheng, L., et al. (2021). New Polyketides from the Antarctic Fungus Pseudogymnoascus sp. HSX2\#-11. Mar. Drugs 19:168.

Skehan, P., Storeng, R., Scudiero, D., Monks, A., Mcmahon, J., Vistica, D., et al. (1990). New colorimetric cytotoxicity assay for anticancer-drug screening. J. Natl. Cancer Inst. 82:1107.

Sun, C.-T., Wang, J.-P., Shu, Y., Cai, X.-Y., Hu, J.-T., Zhang, S.-Q., et al. (2020). A new tremulane sesquiterpene from Irpex lacteus by solid-state fermentation. Nat. Prod. Res. 1-6. doi: 10.1080/14786419.2020.1806272 [Online ahead of print].

Sun, C., Zhang, Z., Ren, Z., Yu, L., and Zhu, T. (2020). Antibacterial cyclic tripeptides from Antarctica-sponge-derived fungus Aspergillus insulicola HDN151418. Mar. Drugs 18:532. 
Tagawa, M., Tamaki, H., Manome, A., Koyama, O., and Kamagata, Y. (2010). Isolation and characterization of antagonistic fungi against potato scab pathogens from potato field soils. FEMS Microbiol. Lett. 305, 136-142. doi: 10.1111/j.1574-6968.2010.01928.x

Wang, F., Ma, H., Hu, Z., Jiang, J., Zhu, H., Cheng, L., et al. (2017). Secondary metabolites from Colletotrichum capsici, an endophytic fungus derived from Siegesbeckia pubescens Makino. Nat. Prod. Res. 31, 1849-1854. doi: 10.1080/ 14786419.2016.1261346

Wang, M., Du, J.-X., Yang, H.-X., Dai, Q., Liu, Y.-P., He, J., et al. (2020). Sesquiterpenoids from cultures of the basidiomycetes Irpex lacteus. J. Nat. Prod. 83, 1524-1531. doi: 10.1021/acs.jnatprod.9b01177

Weng, Y., Lu, J., Xiang, L., Matsuura, A., Zhang, Y., Huang, Q., et al. (2011). Ganodermasides C and D, two new anti-aging ergosterols from spores of the medicinal mushroom Ganoderma lucidum. Biosci. Biotechnol. Biochem. 75, 800-803. doi: 10.1271/bbb.100918

Weng, Y., Xiang, L., Matsuura, A., Zhang, Y., Huang, Q., and Qi, J. (2010). Ganodermasides A and B, two novel anti-aging ergosterols from spores of a medicinal mushroom Ganoderma lucidum on yeast via UTH1 gene. Bioorg. Med. Chem. 18, 999-1002. doi: 10.1016/j.bmc.2009.12.070

Wu, G. (2016). Pharmaceutical composition of citicoline sodium and medicinal application thereof. China Patent No. 105753681A, Jul 13, Jiangsu, China.

Wu, P.-F., Ding, R., Tan, R., Liu, J., Hu, E.-M., Li, C.-Y., et al. (2020). Sesquiterpenes from cultures of the fungus Phellinus igniarius and their cytotoxicities. Fitoterapia 140:104415. doi: 10.1016/j.fitote.2019.10 4415

Wu, X., Lin, S., Zhu, C., Yue, Z., Yu, Y., Zhao, F., et al. (2010). Homo- and heptanorsterols and tremulane sesquiterpenes from cultures of Phellinus igniarius. J. Nat. Prod. 73, 1294-1300.

Wu, Y.-M., Zhou, Q.-Y., Yang, X.-Q., Luo, Y.-J., Qian, J.-J., Liu, S.-X., et al. (2019). Induction of antiphytopathogenic metabolite and squalene production and phytotoxin elimination by adjustment of the mode of fermentation in cocultures of phytopathogenic Nigrospora oryzae and Irpex lacteus. J. Agric. Food Chem. 67, 11877-11882. doi: 10.1021/acs.jafc.9b04209

Xia, Q., Rufty, T., and Shi, W. (2021). Predominant microbial colonizers in the root endosphere and rhizosphere of turfgrass systems: Pseudomonas veronii, Janthinobacterium lividum, and Pseudogymnoascus spp. Front. Microbiol. 12:643904. doi: 10.3389/fmicb.2021.643904

Ying, Y. M., Shan, W. G., Zhang, L. W., and Zhan, Z. J. (2013). Ceriponols A$\mathrm{K}$, tremulane sesquitepenes from Ceriporia lacerate HS-ZJUT-C13A, a fungal endophyte of Huperzia serrata. Phytochemistry 95, 360-367.

Yu, G., Sun, Z., Peng, J., Zhu, M., Che, Q., Zhang, G., et al. (2019). Secondary metabolites produced by combined culture of Penicillium crustosum and a Xylaria sp. J. Nat. Prod. 82, 2013-2017.

Zhou, Q.-Y., Yang, X.-Q., Zhang, Z.-X., Wang, B.-Y., Hu, M., Yang, Y.-B., et al. (2018). New azaphilones and tremulane sesquiterpene from endophytic Nigrospora oryzae cocultured with Irpex lacteus. Fitoterapia 130, 26-30. doi: 10.1016/j.fitote.2018.07.018

Zhou, Z.-Y., Tang, J.-G., Wang, F., Dong, Z.-J., and Liu, J.-K. (2008). Sesquiterpenes and aliphatic diketones from cultures of the basidiomycete Conocybe siliginea. J. Nat. Prod. 71, 1423-1426. doi: 10.1021/np8002657

Conflict of Interest: The authors declare that the research was conducted in the absence of any commercial or financial relationships that could be construed as a potential conflict of interest.

Copyright (c) 2021 Shi, Li, Zheng, Zhang, Dai, Shang, Yu, Zhang, Hu and Shi. This is an open-access article distributed under the terms of the Creative Commons Attribution License (CC BY). The use, distribution or reproduction in other forums is permitted, provided the original author(s) and the copyright owner(s) are credited and that the original publication in this journal is cited, in accordance with accepted academic practice. No use, distribution or reproduction is permitted which does not comply with these terms. 